\title{
CARACTERIZAÇÃO E ANÁLISE DOS ESPAÇOS PÚBLICOS DA CIDADE DE ARAPIRACA-AL-BRASIL
}

\author{
CHARACTERIZATION AND ANALYSIS OF THE PUBLIC SPACES OF \\ ARAPIRACA CITY (ALAGOAS-BRAZIL)
}

\section{CARACTERIZACIÓN Y ANÁLISIS DE LOS ESPACIOS PÚBLICOS DE LA CIUDAD DE ARAPIRACA-AL-BRASIL}

\author{
Marcos Antônio Silvestre Gomes \\ Doutor em Ciências, Análise Ambiental e Dinâmica Territorial \\ Professor Adjunto do Departamento de Geografia da Universidade Federal Fluminense (UFF) \\ Rua José do Patrocínio, 71, Centro - Campos dos Goytacazes-RJ \\ E-mail: msilvestre@id.uff.br \\ Rosineide Nascimento da Silva \\ Bióloga e Mestranda em Ecologia e Conservação pela Universidade Federal de Sergipe (UFS) \\ Av. Marechal Rondon, s/n, Jardim Rosa Elze, \\ São Cristóvão-SE. CEP: 49100-000 \\ E-mail: rosineideg7@gmail.com
}

José Cláudio dos Santos Silva

Graduando em Arquitetura e Urbanismo

Universidade Federal de Alagoas (UFAL)

Av. Manoel Severino Barbosa, s/n, Bom Sucesso, Caixa Postal 61.

Rodovia AL 115 - Km 6,5. Arapiraca-AL. CEP: 57309-005.

E-mail: claudiosantos9@hotmail.com

\section{Thiago Gilney Ferreira Silva}

Graduando em Arquitetura e Urbanismo

Universidade Federal de Alagoas (UFAL)

Av. Manoel Severino Barbosa, s/n, Bom Sucesso, Caixa Postal 61.

Rodovia AL 115 - Km 6,5. Arapiraca-AL. CEP: 57309-005.

E-mail: negueba_war@hotmail.com

\section{Resumo}

Os espaços públicos são parte inerente e fundamental do processo de produção das cidades e, historicamente, nestes espaços se desenvolvem relações de vivência, coletividade e manifestações socioculturais. Assim, este estudo teve o objetivo de caracterizar e analisar os espaços públicos da cidade de Arapiraca-AL, observando critérios como localização na malha urbana, infraestrutura implantada e cobertura vegetal, e também buscou avaliar leis e documentos públicos referentes a estes espaços, 
contribuindo para a reflexão acerca da importância dos mesmos e como subsídio para políticas públicas. Foram realizadas consultas bibliográficas sobre a temática e em documentos públicos, além do levantamento de campo através do preenchimento de formulário específico. Os resultados apontaram que existem significativas diferenças socioespaciais, em infraestrutura, na cobertura vegetal e na manutenção dos espaços pelo poder público. Todavia, de modo geral, apesar da relevância que têm no espaço urbano, caracterizam-se pela carência em infraestrutura e pela necessidade de políticas públicas que resultem na ampliação de suas potencialidades e dos usos pelos usuários.

Palavras-chave: espaços públicos, políticas públicas, Arapiraca.

\begin{abstract}
Historically, the public spaces are importants in the city, in special because they provide the development of collective relations and cultural manifestations. This article had the objective to characterize and to analyze the public spaces of the city of Arapiraca-AL, observing aspects as localization, infrastructure and vegetation. Equally evaluated laws and publics acts about these spaces, contributing for the reflection concerning the importance of the same ones and as subsidy for public politics. Bibliographical consultations about the thematic and surveys of field with specific form had been carried through. The results demonstrate significant socioespaciais differences, in infrastructure, in the vegetal covering and the maintenance of the spaces for the public power. Although, however importants in the city, they are characterized for the lack of infrastructure and the necessity of public politics that optimize its uses.
\end{abstract}

Keywords: public spaces, public politics, Arapiraca.

\title{
Resumen
}

Históricamente, los espacios públicos son parte inherente y fundamental del proceso de producción de las ciudades. En estos espacios desarrollan relaciones de existencia, colectividad y manifestaciones socioculturales. Así, ese estudio tuve el objetivo de caracterizar y analizar los espacios públicos de la ciudad de Arapiraca-AL. Se observó igualmente aspectos como su ubicación, la infraestructura implantada y la cobertura vegetal. Se analizó las leyes y otros documentos públicos referentes a estos espacios. Se espera así contribuir para la reflexión acerca de la importancia de los mismos y proporcionar subsidios para las políticas públicas. Las consultaciones bibliográficas fueron basadas en el tema y en los documentos públicos; las actividades de terreno se realizaron con auxilio de uno formulario específico. Los resultados apuntaron para una significativa diferencia socioespaciale, en la infraestructura, en la cobertura vegetal y en el mantenimiento de los espacios por el poder público. En general, pese la relevancia que los espacios públicos tienen en el espacio urbano, estos se caracterizan por la ausencia de infraestructura y por la necesidad de políticas públicas que resulten en una amplificación de sus potencialidades y de los usos para los usuarios.

Palabras-clave: espacios públicos, políticas públicas, Arapiraca. 


\section{Introdução}

Os espaços públicos são parte inerente e fundamental do processo de produção das cidades. Historicamente, são nestes espaços que se desenvolvem as relações de vivência e coletividade de uma comunidade. Mas também, são espaços que concebidos como áreas verdes podem reforçar a ideia de conservação e preservação da biodiversidade (PINA; SANTOS, 2012).

Como afirma Casé (2000, p. 56), “a importância de uma cidade, avaliada pela sua dimensão social e humana, é proporcional aos atributos urbanos de suas praças e aos predicados arquitetônicos das edificações que a delimitam”.

Praças, parques e outros espaços de lazer são símbolos materializados na paisagem que transcendem ao tempo e ao espaço local. Para Casé (2000), esses espaços públicos podem sinalizar a aglutinação dos encontros, propiciar a vivência e contribuir para o espírito comunitário. Também, podem representar os espaços abstratos, ou como diz Lefebvre (1999, p. 36), "um degradado simulacro do espaço livre, aquele dos encontros e dos jogos..." posto que resultam das estratégias capitalistas de produção do espaço. Como exemplo, podem-se considerar as praças e os parques no interior de bairros ditos nobres, implantados como um produto a ser ofertado no mercado de imóveis ${ }^{1}$.

Segundo Carlos (2003, p. 26), a cidade "aparece como materialidade, produto do processo de trabalho, de sua divisão técnica, mas também da divisão social. É materialização da história dos homens, normatizada por ideologias; é forma de pensar, sentir, consumir; é modo de vida, de uma vida contraditória”.

O valor de uso da cidade e dos espaços públicos coletivos é caracterizado pela predominância das condições históricas em que se processa a produção e o consumo do espaço urbano, antes da cidade ter sido tomada pelo secular processo de industrialização, no qual a cidade e seus componentes eram efetivamente vistos como obra e não como produto (LEFEBVRE, 2006).

O valor de uso deve ser erigido pelo uso comunitário, pela percepção do espaço construído e consumido socialmente, como obra, e não como produto, vendável na sociedade do consumo de massas, como muitas vezes se vê praças e parques, que se

\footnotetext{
${ }^{1}$ Sobre esta questão, veja-se Gomes (2009), Serpa (2007), entre outros.
} 
tornam signos de bairros ou cidades, atrelados à imagem de grandes empreendimentos ou prefeitos empreendedores (SILVA; GOMES, 2010).

Praças e parques são elementos importantes no contexto do espaço urbano. Os parques constituem áreas específicas nas cidades que tanto remetem à conservação da natureza, pois pressupõem o contato do homem com a natureza, quanto se destinam ao lazer ativo e contemplativo. Tais espaços podem constituir instrumentos potenciais para a prática da educação ambiental e seus múltiplos desdobramentos no que tange ao processo de sensibilização, conscientização e, por conseguinte, criticidade dos indivíduos, sobretudo, no que diz respeito às diferentes interpretações sobre o olhar "ambiental".

Como salienta Saldanha (1993, p. 15),

a idéia de praça vai indicar aqui o espaço público, com específico desligamento em relação à moradia privada. As praças, nas cidades construídas em todos os quadrantes e em todos os âmbitos culturais, se ligam a finalidades mais "genéricas": ligam-se ao espaço comum - no sentido 'comunitário' do termo -, ao âmbito político, à finalidade econômica, à dimensão religiosa ou militar da vida social [...]. A óbvia extensão espacial da praça não é apenas extensão espacial: ela corresponde a um significado social, correlato do próprio espírito da cidade onde se insere.

Compreendendo estas questões como pertinentes ao debate, este artigo intenta caracterizar e analisar os espaços públicos da cidade de Arapiraca-AL, notadamente praças e parques, com o intuito de contribuir tanto para a reflexão acerca da importância desses espaços quanto como um instrumental que possa subsidiar políticas públicas municipais. Assim, propõe-se uma caracterização geral dos espaços públicos existentes na malha urbana, considerando localização, infraestrutura implantada e cobertura vegetal, bem como uma análise de leis e documentos públicos referentes a estes espaços.

Especialmente em cidades de médio porte ${ }^{2}$, como Arapiraca-AL, cuja população é de 214.006 habitantes (IBGE, 2010), dos quais 181.481 são urbanos, espaços públicos como parques e praças, especialmente esta última categoria,

\footnotetext{
${ }^{2}$ Há importantes discussões acadêmicas sobre critérios conceituais de cidades médias ou de porte médio. No entanto, para o escopo desta pesquisa, considerando-se Branco (2007), apontamos Arapiraca como cidade de médio porte pelas suas características econômicas, sociais e demográficas na rede urbana regional.
} 
desempenham um papel de maior relevância junto à população, sobretudo, entre as camadas de baixa renda.

Em Arapiraca, a relevância dos espaços públicos para a população de baixa renda ocorre não somente em função da ausência de outras opções de lazer, como cinemas, shoppings centers, teatros, entre outros, mas também pela característica cultural despertada por essa população. Trata-se de uma população marcada por traços culturais que privilegiam o espaço da rua, da praça e do parque, quer seja como o lugar de trocas, de cultos religiosos, de cerimônias cívicas, de conversas informais, de atividades lúdicas e esportivas, quer seja como um espaço que se complementa e se entrecruza às delimitações do espaço privado: a casa.

No espaço urbano de Arapiraca, segundo a Prefeitura Municipal, somente 11,7\% da área total é ocupada por edificações públicas e espaços livres públicos. Somam-se trinta e nove espaços livres públicos que, em geral, se encontram na área central ou nos bairros circunvizinhos, ocupados pelas camadas de médio poder aquisitivo.

Estes dados são reveladores da necessidade, tanto de intervenção pública, no sentido de adotar leis e normas mais eficientes que obriguem a destinação destes espaços, quando do parcelamento do solo, quanto da articulação da sociedade civil no intuito de reivindicar ao poder público, espaços qualitativos para as camadas de média e baixa renda, sobretudo. Também, esta realidade sinaliza a importância deste estudo, uma vez que contribui com dados e análises referentes a esta problemática na cidade.

\section{Caracterização e análise dos espaços públicos de Arapiraca}

O município de Arapiraca, objeto desta análise, está localizado no Agreste alagoano e ocupa área de $356,17 \mathrm{~km}^{2}$, constituindo-se no município de maior importância econômica e demográfica do interior do Estado de Alagoas. Sua sede situase a 264 m de altitude e está a 136 km de Maceió, capital do Estado (Figura 1).

Pode-se afirmar que Arapiraca, de maneira geral, apresenta carências em espaços públicos para o uso coletivo. Esse fato tende a se agravar nos bairros periféricos pobres, cuja população vê-se desprovida da oportunidade de usufruir de espaços públicos necessários ao convívio social. 
Nos órgãos municipais consultados, como Secretarias de Desenvolvimento Urbano e Habitação e de Planejamento, não existe um cadastro sobre estes espaços, indicando suas características gerais, como os tipos e condições dos equipamentos e da cobertura vegetal. No entanto, a existência de um mapa, na escala de 1:10.000, indicando a localização de praças e parques na malha urbana, possibilitou o levantamento de campo que este estudo apresenta à luz de referenciais teóricos.

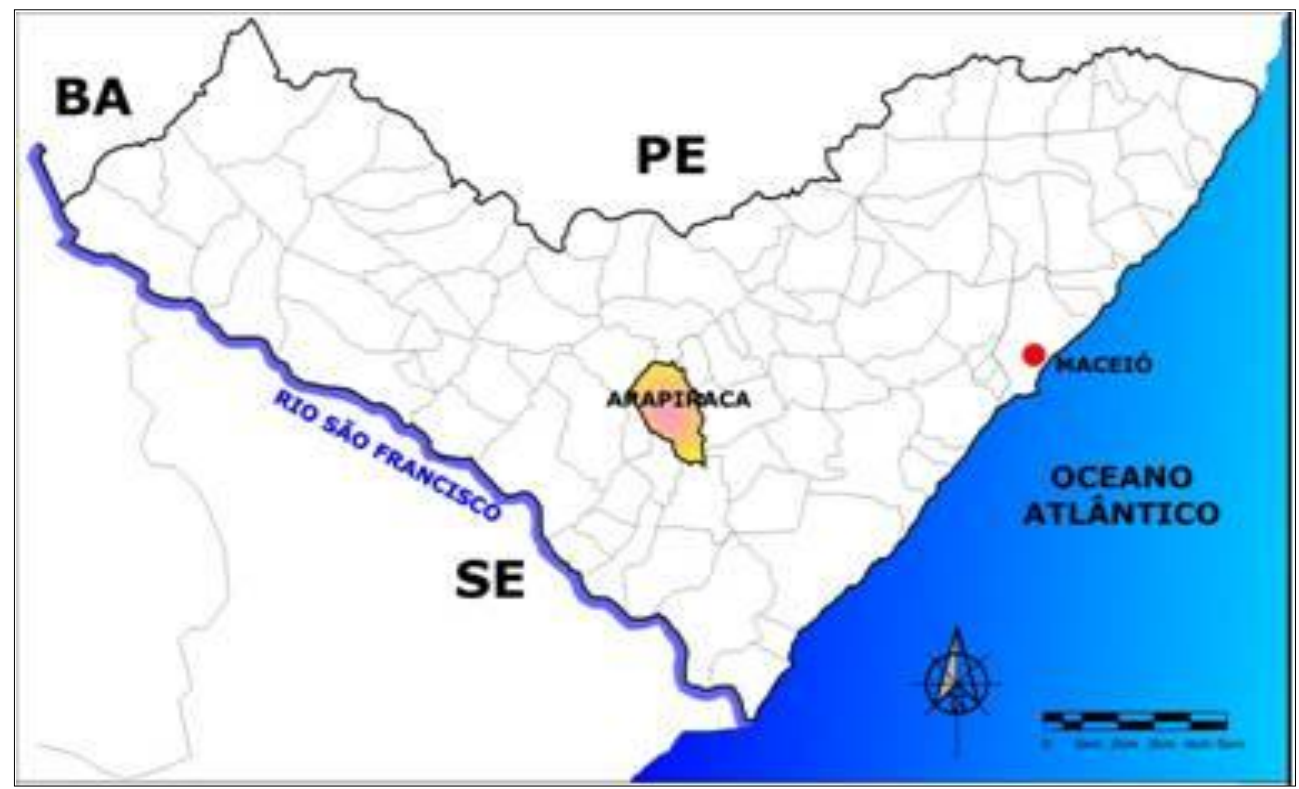

Figura 1: Localização geográfica do município de Arapiraca no Estado de Alagoas. Fonte: Elaboração de Antônio R. N. Júnior com base em dados da Secretaria do Estado de Alagoas de Recursos Hídricos e Irrigação (2002).

Durante as pesquisas de campo foi utilizado um formulário para cada espaço (Anexo 1), registrando-se informações quanto à infraestrutura e vegetação, bem como as condições topográficas, os aspectos paisagísticos, o perfil do imobiliário circunvizinho etc. Este procedimento metodológico, elaborado por Gomes (2005), apresentou resultados satisfatórios para os propósitos deste estudo.

Neste levantamento optou-se por considerar a nomenclatura utilizada pelo poder público, ou seja, praça, parque, área verde etc ${ }^{3}$. Como resultado, a tabela 1 especifica os espaços públicos identificados no espaço urbano de Arapiraca e apresenta

\footnotetext{
3 Foge ao escopo deste trabalho a discussão conceitual sobre as diferentes categorias de espaços públicos, como muitos trabalhos já realizaram, a exemplo de Nucci (2001) e Lima et al. (1994).
} 
algumas características relacionadas aos mesmos ${ }^{4}$. Foram consideradas todas as praças existentes nos bairros, o Parque Municipal Ceci Cunha e a Área Verde Dom Constantino Lerns.

Conforme a tabela 1, 41,7\% dos espaços públicos analisados encontram-se em área de perfil imobiliário de médio padrão, 27,8\% de baixo padrão, $19,4 \%$ de médio/baixo padrão e $11,1 \%$ de alto padrão. Estes resultados sinalizam que cerca de $72,2 \%$ destes espaços podem estar localizados entre as camadas de rendas média e alta.

De acordo com a referida tabela, $86,0 \%$ dos espaços ocupam terreno plano, o que se apresenta como um fator importante para a alocação de determinadas estruturas, possibilitando usos variados destes espaços. Para tal finalidade, a forma geométrica das praças e do parque também pode ser relevante: 58,3\% têm forma triangular, 19,4\% retangular, $8,3 \%$ quadrangular, $2,8 \%$ circular e $11,1 \%$ outra forma geométrica.

\footnotetext{
${ }^{4}$ A análise qualitativa dos elementos presentes nos espaços públicos considerou suas características gerais, sua composição e sua harmonia com a dimensão do espaço.
} 
Tabela 1 - Caracterização geral dos espaços públicos em Arapiraca-AL

\begin{tabular}{|c|c|c|c|c|c|c|c|c|}
\hline & Bairro & Logradouro & $\begin{array}{l}\text { Perfil do } \\
\text { imobiliário }\end{array}$ & Topografia & $\begin{array}{l}\text { Forma } \\
\text { Geométrica }\end{array}$ & $\begin{array}{l}\text { Aspecto } \\
\text { Geral }\end{array}$ & $\begin{array}{l}\text { Aspecto } \\
\text { paisagístico }\end{array}$ & $\begin{array}{l}\text { Cobertura } \\
\text { Vegetal }\end{array}$ \\
\hline 1 & Alto do Cruzeiro & Praça Memorial da Mulher & Médio & Íngreme & Triangular & Ótimo & Bom & Satisfatória \\
\hline 2 & Alto do Cruzeiro & Praça Santa Cruz & Médio & Íngreme & Triangular & Regular & Bom & Satisfatória \\
\hline 3 & Alto do Cruzeiro & $\begin{array}{l}\text { Praça Rua Sebastião Ribeiro } \\
\text { Barbosa }\end{array}$ & Alto & Plana & Triangular & Péssimo & Ruim & Insatisfatória \\
\hline 4 & Baixa Grande & Praça Juvenal Cunha & Médio Baixo & Plana & Triangular & Ótimo & Bom & Satisfatória \\
\hline 5 & Baixão & Praça Rua José Alexandre & Médio & Plana & Retangular & Bom & Bom & Satisfatória \\
\hline 6 & Boa Vista & $\begin{array}{l}\text { Praça Pedro Marinho Muniz } \\
\text { Suruagy }\end{array}$ & Baixo & Plana & Triangular & Péssimo & Ruim & Insatisfatória \\
\hline 7 & Brasília & Praça Santa Rosa & Médio & Plana & Outra & Ruim & Ruim & Insatisfatória \\
\hline 8 & Brasília & Praça Lions Club & Alto & Plana & Circular & Bom & Bom & Insatisfatória \\
\hline 9 & Brasília & Praça Edmundo Félix da Silva & Médio Baixo & Plana & Triangular & Péssimo & Ruim & Insatisfatória \\
\hline 10 & Brasília & $\begin{array}{l}\text { Praça Ver. Euclides Feliciano da } \\
\text { Silva }\end{array}$ & Médio Baixo & Plana & Triangular & Ruim & Ruim & Satisfatória \\
\hline 11 & Brasília & Praça Ver. José Ferreira Barbosa & Alto & Plana & $\begin{array}{l}\text { Quadrangula } \\
\mathrm{r}\end{array}$ & Regular & Regular & Insatisfatória \\
\hline 12 & Cacimbas & Praça Pereira Magalhães & Baixo & Plana & Triangular & Regular & Regular & Satisfatória \\
\hline 13 & Cacimbas & $\begin{array}{l}\text { Praça Rua Ver. Benício A. de } \\
\text { Oliveira }\end{array}$ & Médio & Íngreme & Triangular & Bom & Bom & Satisfatória \\
\hline 14 & Caetetus & $\begin{array}{l}\text { Praça Rua Pedro Correia das } \\
\text { Graças }\end{array}$ & Médio & Plana & Triangular & Bom & Regular & Satisfatória \\
\hline 15 & Cavaco & $\begin{array}{l}\text { Praça Antônio Ventura Oliveira } \\
\text { Filho }\end{array}$ & Baixo & Plana & Triangular & Péssimo & Ruim & Insatisfatória \\
\hline 16 & Centro & Praça José Pereira Leão & Médio & Plana & Outra & Ruim & Ruim & Insatisfatória \\
\hline 17 & Centro & Praça Marques da Silva & Médio & Plana & Outra & Bom & Bom & Satisfatória \\
\hline 18 & Centro & Praça Manoel André & Médio & Plana & Retangular & Ótimo & Bom & Satisfatória \\
\hline 19 & Centro & Praça Luiz Pereira Lima & Médio & Plana & Retangular & Regular & Regular & Satisfatória \\
\hline 20 & $\begin{array}{l}\text { Centro/Alto } \\
\text { Cruzeiro }\end{array}$ & Parque Municipal Ceci Cunha & Médio & Plana & Retangular & Ótimo & Bom & Satisfatória \\
\hline 21 & Eldorado & Praça Padre Cícero & Baixo & Plana & Triangular & Péssimo & Ruim & Insatisfatória \\
\hline 22 & Eldorado & $\begin{array}{l}\text { Praça Rua Expedicionários } \\
\text { Brasileiros }\end{array}$ & Médio Baixo & Plana & Triangular & Ruim & Ruim & Satisfatória \\
\hline
\end{tabular}

Ateliê Geográfico Goiânia-GO v. 6,n. 4 Dez/2012 $\quad$ p.137-157 Página 144


ISSN: $1982-1956$

앙용

\begin{tabular}{|c|c|c|c|c|c|c|c|c|}
\hline 23 & Eldorado & Praça Rua Atílio V. B. dos Santos & Médio & Plana & Retangular & Regular & Regular & Satisfatória \\
\hline 24 & Guaribas & $\begin{array}{l}\text { Praça Av. João Saturnino } \\
\text { Almeida }\end{array}$ & Médio Baixo & Plana & Triangular & Regular & Regular & Satisfatória \\
\hline 25 & Jardim Esperança & Praça Av. José A. da Silva & Baixo & Plana & Triangular & Péssimo & Ruim & Insatisfatória \\
\hline 26 & Jardim Esperança & Praça Av. José Emídio de Lima & Baixo & Plana & $\begin{array}{l}\text { Quadrangula } \\
\text { r }\end{array}$ & Ruim & Ruim & Insatisfatória \\
\hline 27 & Jardim Esperança & $\begin{array}{l}\text { Praça Lercino Nunes de } \\
\text { Albuquerque }\end{array}$ & Baixo & Plana & Triangular & Regular & Regular & Insatisfatória \\
\hline 28 & Jardim Esperança & Praça Manoela Cordeiro de Lima & Baixo & Plana & Triangular & Bom & Bom & Insatisfatória \\
\hline 29 & Jardim Tropical & Praça Afrânio Salgado Lages & Médio & Plana & Outra & Bom & Regular & Satisfatória \\
\hline 30 & Nova Esperança & Praça Carlos Gomes & Baixo & Plana & Outra & Péssimo & Ruim & Insatisfatória \\
\hline 31 & Nova Esperança & Praça Edmilson da Rocha Barros & Baixo & Plana & Outra & Péssimo & Ruim & Insatisfatória \\
\hline 32 & Novo Horizonte & $\begin{array}{l}\text { Área Verde Dom Constantino } \\
\text { Lerns }\end{array}$ & Alto & Plana & Retangular & Ótimo & Bom & Satisfatória \\
\hline 33 & Ouro Preto & Praça Santa Rosa & Médio & Íngreme & Triangular & Péssimo & Ruim & Insatisfatória \\
\hline 34 & Primavera & Praça Rua Marechal Costa e Silva & Baixo & Plana & Triangular & Péssimo & Ruim & Insatisfatória \\
\hline 35 & Primavera & Praça Rua Paulo Afonso & Médio Baixo & Plana & Triangular & Ruim & Ruim & Insatisfatória \\
\hline 36 & Primavera & Praça Rua Costa Gama & Baixo & Ingreme & Triangular & Péssimo & Ruim & Insatisfatória \\
\hline 37 & Primavera & Praça Rua Estudante José Acácio & Baixo & Plana & Triangular & Péssimo & Ruim & Insatisfatória \\
\hline 38 & Santa Esmeralda & $\begin{array}{l}\text { Praça Menino Jesus Maximiano } \\
\text { Silva }\end{array}$ & Médio & Plana & $\begin{array}{l}\text { Quadrangula } \\
\mathrm{r}\end{array}$ & Regular & Regular & Insatisfatória \\
\hline 39 & São Luiz II & Praça Juraci Camelo dos Santos & Médio Baixo & Plana & Retangular & Ruim & Ruim & Satisfatória \\
\hline
\end{tabular}

Ateliê Geográfico Goiânia-GO v. 6,n. 4 Dez/2012 $\quad$ p.137-157 Página 145


A grande variedade de formas que os terrenos destes espaços assumem elucida a irregular composição das quadras no interior da cidade, fato que tende a comprometer as potencialidades de usos desses espaços, em geral, porque encontram-se em bifurcação de ruas, rotatórias etc., e também porque ocupam áreas de dimensões reduzidas.

Considerando-se o aspecto geral dos espaços, identificou-se $25,0 \%$ péssimos, $19,4 \%$ bons, $19,4 \%$ ruins, $22,2 \%$ regulares e 14,0\% ótimos, ou seja, apenas 55,6\% apresentam uma estrutura relativa de conforto ao usuário, considerando-se aspectos de infraestrutura e tratamento paisagístico. Deve-se ressaltar que, estes dados embasaramse somente na percepção dos pesquisadores durante o levantamento de campo.

A pesquisa de campo, como demonstra a tabela 1, contemplou dezoito bairros de Arapiraca, nos meses de março e abril de 2010 e contabilizou trinta e nove espaços públicos, sendo 37 praças, 01 parque e 01 área verde. A quantidade de bairros selecionada e visitada teve como critério a presença destes espaços. Entretanto, alguns bairros durante as visitas não apresentavam os espaços apontado no mapa da Prefeitura, sendo estes bairros desconsiderados. A zona urbana do município é composta de trinta e oito bairros, segundo a Lei Municipal no. 2470/2006 (PREFEITURA MUNICIPAL DE ARAPIRACA, 2006a).

Observa-se, na figura 2, que há uma concentração dos espaços públicos em bairros como Brasília, Centro e Alto do Cruzeiro, demonstrando que a distribuição é irregular na malha urbana. Bairros periféricos pobres como Planalto, Manoel Teles, Canafístula, Senador Nilo Coelho, dentre outros, não dispõem de praças ou parques, o que evidencia a ineficiência das políticas públicas.

Com o objetivo de uma análise qualitativa dos espaços públicos, neste estudo avaliou-se também aspectos quanto à sua situação geral, considerando infraestrutura e vegetação (Tabelas 2 e 3$)^{5}$.

\footnotetext{
${ }^{5}$ Devido a três praças (Pedro Marinho Muniz Suruagy, no bairro Boa Vista, Carlos Gomes e Edmilson da Rocha Barros, ambas no Bairro Nova Esperança) apresentarem-se como terrenos baldios, sem cobertura arbórea ou equipamentos de infraestrutura, considerou-se para os cálculos destas informações presentes nas tabelas 2 e 3 o total de 36 espaços públicos.
} 


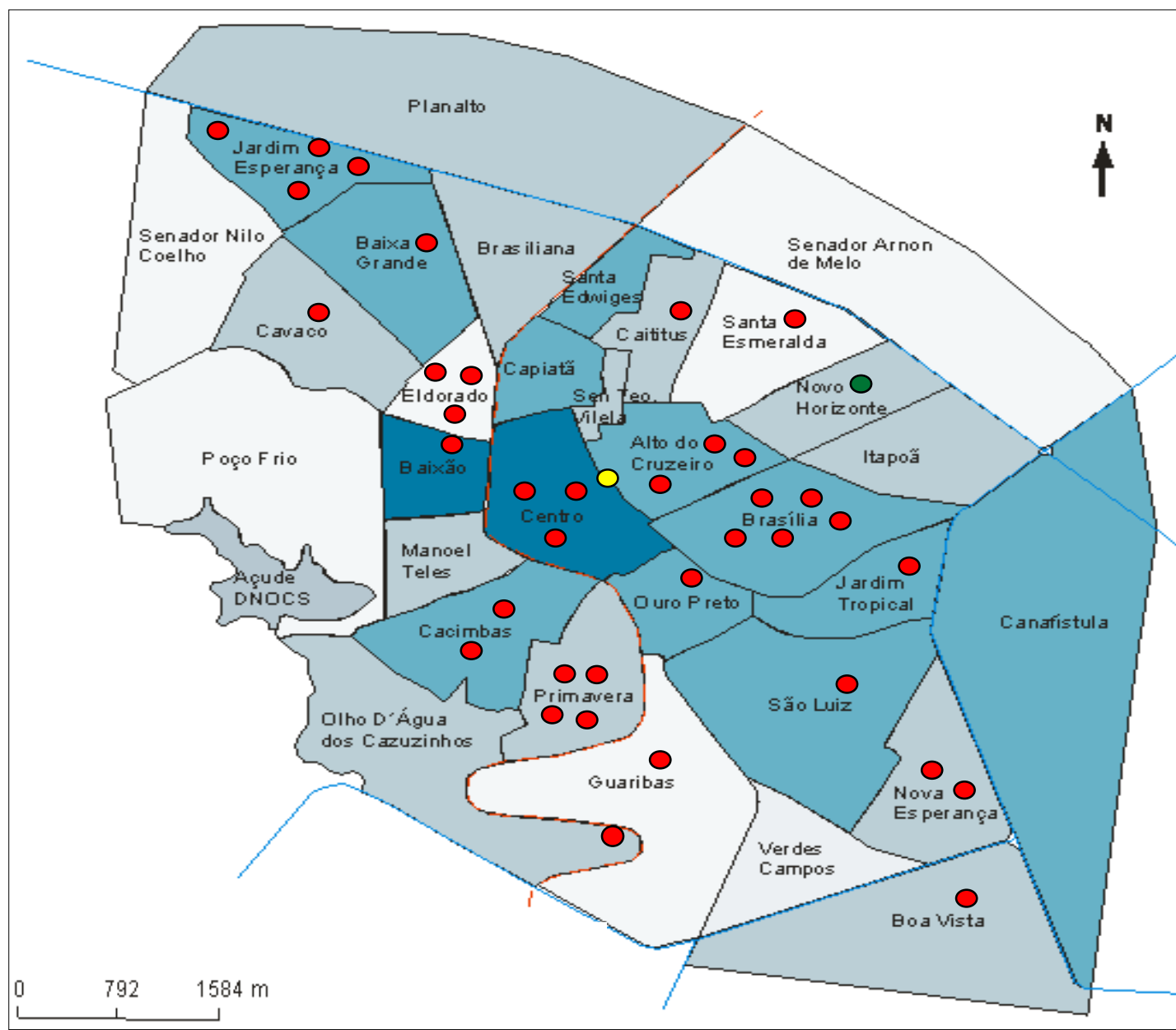

Figura 2. Perímetro urbano de Arapiraca, destacando a quantidade de praças por bairros (círculos vermelhos), o parque (círculo amarelo) e a área verde (círculo verde). Fonte: Baseado na malha urbana fornecida pela Prefeitura Municipal de Arapiraca (2007). Adaptação: Rosineide Nascimento da Silva.

Tabela 2 - Representação percentual dos equipamentos existentes em espaços públicos da cidade de Arapiraca-AL

\begin{tabular}{l|c}
\multicolumn{1}{c|}{ Equipamentos existentes } & Percentual \\
\hline Iluminação & 88,9 \\
\hline Bancos & 91,7 \\
\hline Playgrounds & 11,1 \\
\hline Calçadas/caminhos & 91,7 \\
\hline Lixeiras & 47,2 \\
\hline Banheiros/sanitários & 2,8 \\
\hline Estruturas esportivas (barras, etc.) & 11,1 \\
\hline Estruturas para idosos (jogos, etc.) & 13,9 \\
\hline Estruturas para deficientes & 33,3 \\
\hline Segurança pública (guardas, etc.) & 16,7 \\
\hline
\end{tabular}

Fonte: Levantamento de campo (2010). Org.: Rosineide Nascimento da Silva. 
Tabela 3 - Representação percentual da vegetação existente em espaços públicos da cidade de Arapiraca-AL

\begin{tabular}{l|c}
\hline \multicolumn{1}{c|}{ Vegetação } & Percentual \\
\hline Árvore de grande porte & 58,3 \\
\hline Árvore de médio porte & 63,9 \\
\hline Árvore de pequeno porte & 55,6 \\
\hline Árvores frutíferas & 19,4 \\
\hline Estratos arbustivos/flores & 55,6 \\
\hline Gramado & 58,3 \\
\hline
\end{tabular}

Fonte: Levantamento de campo (2010). Org.: Rosineide Nascimento da Silva.

Observa-se na tabela 2 a existência dos equipamentos presentes nos espaços públicos, no entanto, não se considerou o estado de conservação destes equipamentos, dados os objetivos do trabalho. Identificou-se equipamentos básicos como bancos em 91,7\% destes espaços, calçadas/caminhos em 91,7\% e iluminação em 88,9\%. Os equipamentos destinados a grupos específicos de usuários, como crianças, jovens ou adultos, idosos e pessoas com deficiências físicas, geralmente, são insuficientes ou inexistentes. Os playgrounds e as estruturas esportivas estão em apenas 11,1\% dos espaços, as estruturas para idosos representam $13,9 \%$ dos equipamentos existentes e as estruturas para deficientes, $33,3 \%$.

Além disso, nota-se em muitos destes locais uma significativa carência em banheiros/sanitários, lixeiras e segurança pública, tendo em vista que estes elementos foram notados, respectivamente, em 2,8\%, 47,2\% e 16,7\%, dos espaços visitados. Essas constatações podem justificar a subutilização de muitos desses espaços que se tornam pouco atrativos devido a carências de infraestrutura diversificada e de bom estado de conservação. A esse respeito, Ugeda Júnior e Amorim (2011) relatam que o desuso de espaços públicos pela maioria da população atrai outras atividades, como o uso de entorpecentes, que podem gerar aumento e concentração da criminalidade em determinados locais.

Outro fator relevante analisado nos espaços refere-se à presença de vegetação, conforme demonstrado na tabela 3. A maior percentagem é de árvores de médio porte $(63,9 \%)$, seguida de árvores de grande porte $(58,3 \%)$ e de pequeno porte $(55,6 \%)$.

Apesar da diversificação no porte da vegetação, os problemas que envolvem a arborização são variados, como demonstrou Silva (2011) ao observar que as árvores dos 
principais espaços públicos da área central de Arapiraca sofrem com o ataque de diferentes organismos com potencial fitopatogênico (fungos, formigas, cupins e outros); com a caiação (pintura do caule com cal tóxica); com podas irregulares praticadas por pessoas não treinadas; com conflitos entre a arborização e a iluminação, pavimentação e sinalização etc.

Para Romani et al. (2012), por exemplo, solucionar problemas fitossanitários da arborização é imprescindível para evitar acidentes com os usuários dos espaços públicos, bem como é uma necessidade para manter uma vegetação sadia e com atributos paisagísticos. Todavia, os resultados obtidos no presente estudo evidenciam, segundo Ugeda Júnior e Amorim (2011), a negligência do poder público com os espaços coletivos, representada pela falta de cuidados adequados com a vegetação, com os equipamentos existentes, ou com a falta de limpeza e conservação desses espaços.

Embora tenha se verificado nos locais de estudo estratos arbustivos/flores e gramado em quantidade significativa, respectivamente, 55,6\% e 58,3\%, também não foram considerados os aspectos qualitativos dessa cobertura vegetal.

A menor percentagem obtida refere-se às árvores frutíferas $(19,4 \%)$. Segundo Silva (2011), as justificativas relacionam-se à preocupação quanto à integridade física dos usuários desses locais, pois espécies com frutos grandes e relativamente pesados podem aumentar os riscos de acidentes devido a sua abscisão ou produção e eliminação de substâncias irritativas, entre outros. Árvores frutíferas também são concebidas como uma fonte de sujeira quando seu fruto cai em calçadas ou caminhos e bancos, ou seja, pouco se considera suas potencialidades ecológicas.

Conforme Yamamoto et al. (2004, p. 5), “[...] onde existem poucas árvores, existem poucas espécies de pássaros”. Isso porque muitas aves precisam dos frutos produzidos pelas árvores para se alimentarem. Além disso, as copas das árvores são locais seguros para a nidificação. Para Rezende e Santos (2010), uma forma de diagnosticar as potencialidades da arborização quanto a atração e a manutenção da fauna é avaliar a presença de flores e frutos.

As figuras 3 e 4 demonstram os aspectos variados em infraestrutura e vegetação em diferentes espaços públicos de Arapiraca.

As figuras não sinalizam apenas diferenças qualitativas entre espaços, mas demonstram uma realidade no conjunto espacial urbano, ou seja, as praças e parques 
melhor equipados e arborizados localizam-se nos bairros centrais, circunvizinhos ou outros ocupados pela população de maior poder aquisitivo. Nos bairros de periferia pobre, em geral, os espaços são precários, com ausência de equipamentos básicos e de lazer e tratamento paisagístico.

Da mesma forma que os espaços aparecem desigualmente distribuídos em Arapiraca, a vegetação também funciona como um indicativo dessa diferenciação urbana. Como se observa na tabela 1, 21 dos 39 espaços apresentam cobertura vegetal insatisfatória. Ainda, considerando-se o aspecto paisagístico geral dos mesmos, 44,4\% destes apresentam-se como ruins, $30,6 \%$ bons e $25,0 \%$ regulares.

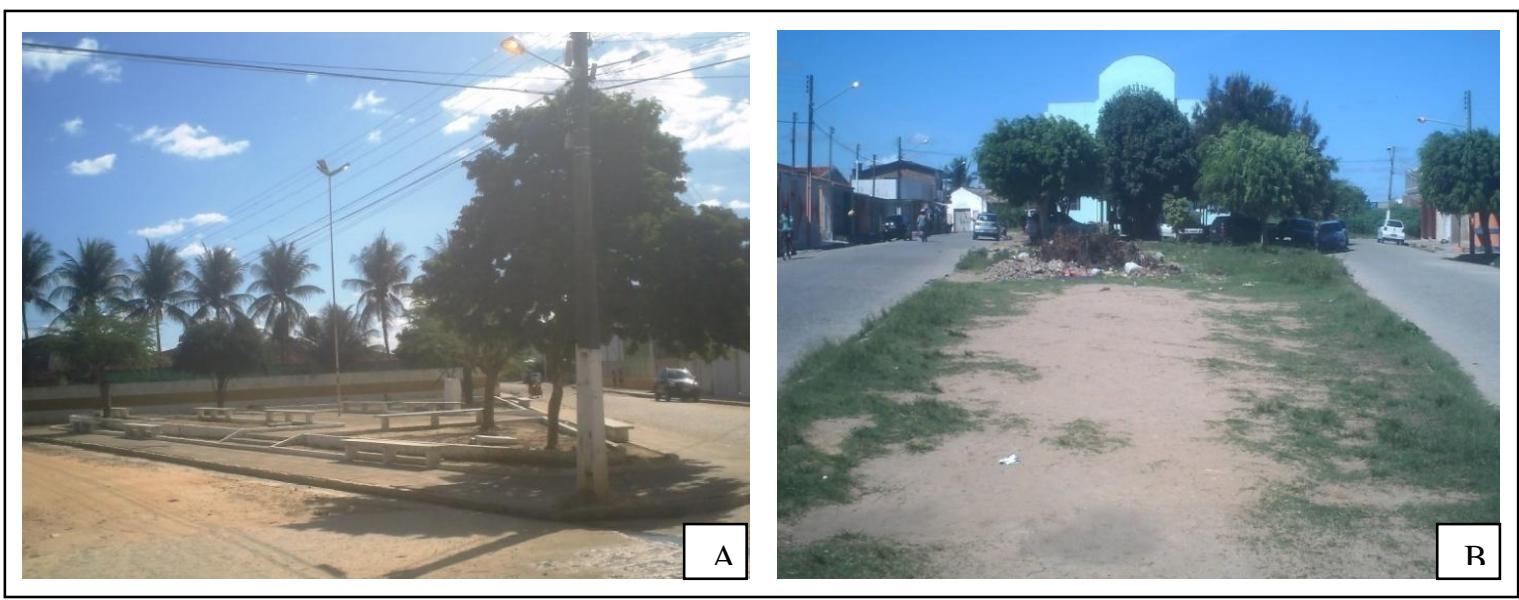

Figura 3. A) Aspecto geral da Praça na Rua Sebastião Ribeiro Barbosa, bairro Alto do Cruzeiro, cuja precariedade em vegetação e equipamentos em geral torna-se marcante. B) Vista panorâmica da Praça Vereador Euclides Feliciano da Silva, no bairro Brasília, que apresenta carências em equipamentos, cobertura vegetal e possui entulho acumulado.

Fonte: Fotos de Thiago G. F. Silva, durante pesquisa de campo (2010).

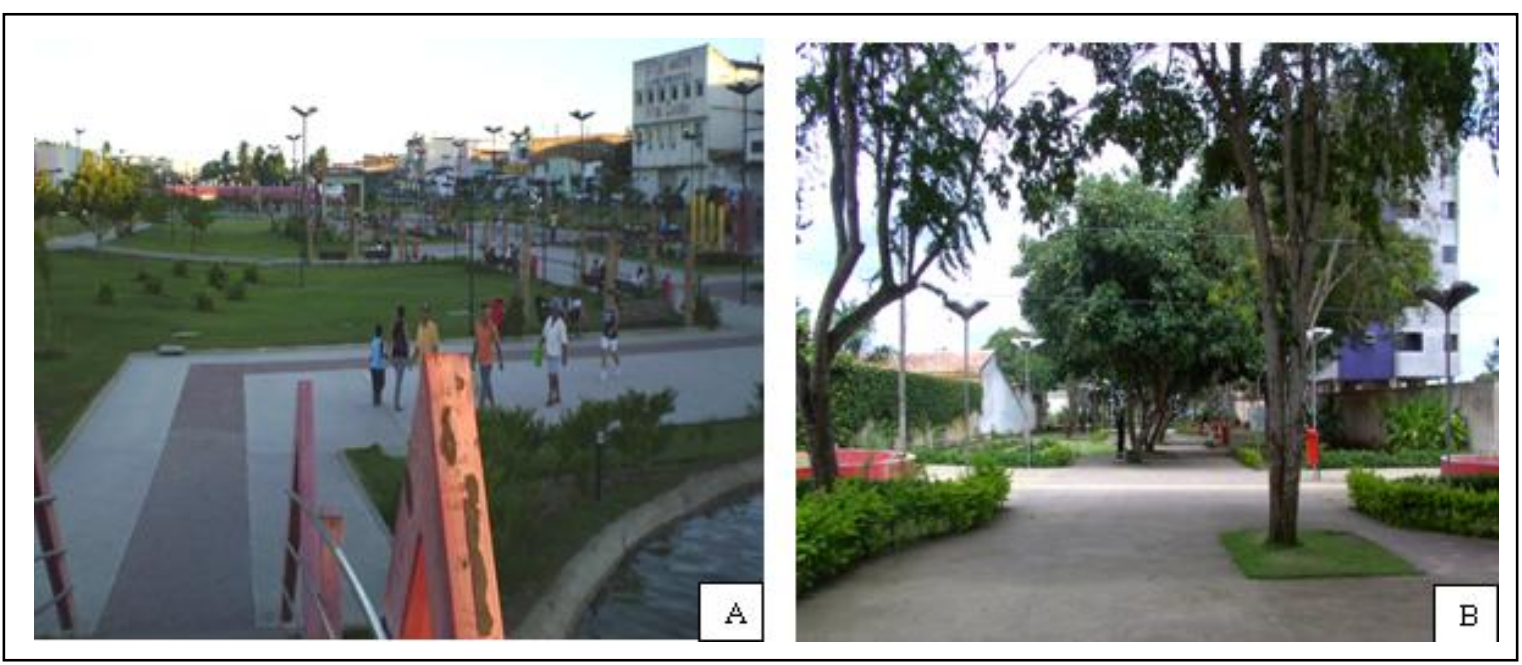

Figura 4. A) Aspecto geral da infraestrutura do Parque Municipal Ceci Cunha. Fonte: Levantamento de campo (2008). Foto: Luana T. S. Farias. B) Vista panorâmica da Área Verde Dom Constantino Lerns.

Fonte: Fotos de Carla C. F. Pessoa, durante pesquisa de campo (2010). 
Segundo Henrique (2006, p. 69),

Cria-se uma diferenciação espacial da natureza na cidade de acordo com a estratificação social. Enquanto nas áreas nobres e valorizadas tanto dos centros quanto das periferias urbanas ricas o que se vê é uma natureza trabalhada e bem cuidada - tanto sob a forma de jardins ingleses, franceses ou bosques e lagos, um lugar para passeio e exibição, um lugar de prestígio -, nos bairros menos abastados, nas vilas, nos conjuntos habitacionais e nas periferias pobres, a natureza bruta (ou o mato?) e ainda 'não controlada' fazse presente, trazendo enchentes, inundações, doenças e frio.

Este fato demonstra que as parcelas do espaço urbano melhor assistidas pelo poder público são habitadas pelas classes com padrões de vida considerados médio e alto, enquanto que as mazelas socioambientais tornam-se mais comuns e evidentes nas áreas ocupadas pelas classes menos abastadas. Neste caso, a natureza, algumas vezes, aparece como ameaça à vida, como se observa em situações de deslizamentos de encostas, enchentes, matagal sem manutenção etc.

Documentos públicos, como Plano Diretor Municipal (PREFEITURA MUNICIPAL DE ARAPIRACA, 2006b - Lei nº. 2424/2006), Agenda 21 (ROMÃO, 2008), Relatório das Características Ambientais (PREFEITURA MUNICIPAL DE ARAPIRACA, 2006c) e Dossiê Urbano Habitacional e Ambiental (PREFEITURA MUNICIPAL DE ARAPIRACA, 2004), apontam que Arapiraca possui elevada deficiência quanto à arborização de ruas, avenidas e espaços públicos (Tabela 4). No referido dossiê consta que a avaliação dessa deficiência fundamentou-se apenas na realização de observações durante levantamentos de campo e informações encontradas em fotografias. No entanto, por ser um dado oficial, optou-se por considerar nesta análise. 
Tabela 4 - Percentual da carência de arborização em alguns bairros da cidade de Arapiraca-AL

\begin{tabular}{c|c}
\hline Bairros & Carência de arborização (\%) \\
\hline Centro & 98,8 \\
\hline Alto do Cruzeiro & 96,4 \\
\hline Brasília & 94,0 \\
\hline Ouro Preto & 95,3 \\
\hline Baixão & 96,7 \\
\hline Cacimbas & 94,1 \\
\hline Primavera & 97,9 \\
\hline São Luís I & 100,0 \\
\hline São Luís II & 96,6 \\
\hline Novo Horizonte & 95,35 \\
\hline Eldorado & 96,4 \\
\hline Baixa Grande & 98,2 \\
\hline Jardim Esneranca & 98.7
\end{tabular}

Fonte: Dossiê Urbano Habitacional e Ambiental de Arapiraca (Prefeitura Municipal de Arapiraca, 2004). Org.: Rosineide Nascimento da Silva.

$\mathrm{Na}$ tabela 4, os bairros Centro e Novo Horizonte apresentam-se com alta deficiência de arborização, 98,8\% e 95,35\%, respectivamente. No entanto, trata-se de bairros onde se localizam os principais espaços públicos da cidade. Essa situação de carência não se restringe a esses bairros, mas refletem o quadro preocupante da incipiente cobertura vegetal arbórea na cidade, em especial quando se considera arborização de ruas.

A distribuição irregular de árvores na cidade ocorre por motivos diversos, podendo estar relacionada a aspectos culturais, políticos e econômicos. Mesmo em espaços públicos que potencialmente deveriam estar arborizados, como as praças na Rua Sebastião Ribeiro Barbosa (Alto do Cruzeiro) e na Av. José Emídio de Lima (Jardim Esperança), nota-se que as árvores são escassas e quando existem podem apresentar determinados problemas, como a baixa riqueza de espécies, introdução e proliferação de espécies exóticas, aumento e dispersão dos efeitos fitossanitários que podem provocar a morte do vegetal etc.

Uma questão importante analisada por Silva (2011) refere-se à riqueza (número de espécies) arbórea nos espaços públicos da área central de Arapiraca, onde a autora 
registrou uma baixa riqueza. Nas principais praças do centro de Arapiraca (Praças Luiz Pereira Lima, Deputado Marques da Silva e Manoel André), por exemplo, a maior abundância arbórea é representada por três ou quatro espécies (SILVA, 2012). Isto indica uma vulnerabilidade da arborização em espaços públicos da cidade, que pode contribuir com o aumento da capacidade de introdução e desenvolvimento de organismos causadores de doenças em árvores, como fungos, cupins e outros.

As políticas públicas referentes aos espaços públicos favoreceram atividades de lazer e recreação, em detrimento da questão ambiental que os perpassam. Os aspectos estético-paisagísticos são reafirmados como prioridades no Código de Meio Ambiente do Município (Lei no ${ }^{\circ}$ 2221/2001), pois no artigo 67, capítulo III, enfatiza a importância das áreas verdes e dos espaços públicos para o lazer ativo ou contemplativo da população e a manutenção da beleza paisagística de Arapiraca.

Nas duas últimas gestões municipais (2005-2008 e 2009-2012), a criação e implantação de espaços como praças e parques adentrou a agenda pública de modo que se tornou uma política visível na cidade. Apesar de positivo, isto não foi suficiente para reduzir as desigualdades na distribuição e qualidade desses espaços na área urbana. A implantação e reforma em praças e parques ocorreram, sobretudo, na área central e em áreas de interesse da gestão pública ou de classes específicas, como a Praça Memorial da Mulher, o Parque Municipal Ceci Cunha, a Área Verde Dom Constantino Lerns, o Bosque das Arapiracas ${ }^{6}$ e o Parque Lago da Perucaba, implantado às margens do Açude Dnocs, conforme figura 2.

\section{Considerações Finais}

A análise da dinâmica dos espaços públicos nas cidades torna-se um instrumento relevante que explica, em muitos casos, suas funções, seus simbolismos e características. Este estudo identificou nos espaços públicos, objetos desta análise, que os mesmos possuem aspectos tanto distintos quanto semelhantes, quando considerados os bairros onde se localizam e os interesses agregados. Em Arapiraca, os espaços públicos são reveladores da diferenciação socioespacial urbana. Encontram-se, em sua

\footnotetext{
${ }^{6}$ Este bosque é extensão do Parque Municipal Ceci Cunha e não foi contabilizado entre os espaços públicos da tabela 1 porque estava em início de implantação quando o trabalho empírico foi realizado. O Parque Lago da Perucaba também não foi considerado na tabela 1 porque o mapa cedido pela Prefeitura não o considerou como um dos espaços públicos da cidade. Além disso, estava em fase de implantação.
} 
maioria, quantitativa e qualitativamente, nos bairros centrais e circunvizinhos, em geral, ocupados pelas camadas de média e alta renda.

Dentre as questões que merecem destaque na pauta dessa discussão, têm-se a distribuição irregular das praças e parques pela cidade e a acumulação de problemas diversos na composição paisagística e no mobiliário existente. Estes problemas aparecem suavizados no Parque Municipal Ceci Cunha e na Área Verde D. Constantino Lerns, tendo em vista que foram estrategicamente implantados segundo interesses de gestores públicos em criar símbolos de gestão e assim se destacam pela localização no centro da cidade e pelas funções diversificadas que assumem.

As praças da cidade, em geral, são marcadas pela precariedade em equipamentos urbanos, estruturas de lazer/recreação, cobertura vegetal, o que reflete as deficiências das políticas públicas na manutenção desses locais.

Esta análise pretendeu também contribuir com o poder público municipal fornecendo elementos importantes para a elaboração de medidas que objetivem a otimização e organização dos espaços públicos em Arapiraca, tendo em vista que não existem documentos específicos e trabalhos que tratem destes espaços.

\section{Referências Bibliográficas}

BRANCO, M. L. G. C. Algumas considerações sobre a identificação de cidades médias. In: SPOSITO, M. E. B. (org.). Cidades médias: espaços em transição. São Paulo: Expressão Popular, 2007.

CARLOS, A. F. A. A cidade. São Paulo: Contexto, 2003.

CASÉ, P. A cidade desvendada: reflexões e polêmicas sobre o espaço urbano: seus mistérios e fascínios. Rio de Janeiro: Ediouro, 2000.

GOMES, M. A. S. Parques urbanos de Ribeirão Preto-SP: Na produção do espaço, o espetáculo da natureza. Tese (Doutorado em Geografia). Universidade Estadual de Campinas: IGE. São Paulo, 2009.

GOMES, M. A. S. As praças de Ribeirão Preto-SP: uma contribuição geográfica ao planejamento e à gestão dos espaços públicos. Dissertação (Mestrado em Geografia). Universidade Federal de Uberlândia. Uberlândia, 2005.

HENRIQUE, W. A cidade e a natureza: a apropriação, a valorização e a sofisticação da natureza nos empreendimentos imobiliários de alto padrão em São Paulo. Revista 
Geousp. São Paulo, n. 20: 65-77, 2006. Disponível em: <http://www.geografia.ffch.usp.br>. Acesso em: jan. 2011.

INSTITUTO BRASILEIRO DE GEOGRAFIA E ESTATÍSTICA-IBGE. 2011. Disponível: <http://www.ibge.gov.br>. Acesso em: fev. 2012.

LEFEBVRE. H. A Revolução urbana. Belo Horizonte: UFMG, 1999.

LEFEBVRE, H. O direito à cidade. $4^{\mathrm{a}}$ ed. São Paulo: Centauro, 2006.

LIMA, A. M. L. P. et al. Problemas de utilização na conceituação de termos como espaços livres, áreas verdes e correlatos. In: II CONGRESSO BRASILEIRO DE ARBORIZAÇÃO URBANA, 2., 1994, São Luís. Anais... São Luís, 1994, p. 539-553.

NUCCI, J. C. Qualidade ambiental e adensamento urbano. São Paulo: Humanitas/FAPESP, 2001.

PINA, J. H. A.; SANTOS, D. G. A influência das áreas verdes urbanas na qualidade de vida: o caso dos Parques do Sabiá e Victório Siquierolli em Uberlândia-MG. Revista Ateliê Geográfico, Goiânia, v. 6 (1): 43-169, 2012.

PREFEITURA MUNICIPAL DE ARAPIRACA. Dossiê urbano habitacional e ambiental do Município de Arapiraca-AL. Cooperativa de Trabalhadores Ambientalistas. Maceió, 2004.

. Lei $\mathrm{n}^{\circ} .2470$, de 22 de Dezembro de 2006. Dispõe sobre as alterações dos perímetros da zona urbana do município de Arapiraca e seus bairros, definindo-os e nomeando-os e adota providências correlatas. Arapiraca, $2006 a$.

Lei n . 2424, de 23 de Janeiro de 2006b. Institui o Plano Diretor do Município de Arapiraca, estabelece as diretrizes gerais da política de desenvolvimento urbano e dá outras providências. Arapiraca, 2006.

Lei $n^{\circ} .2221$, de 31 de Dezembro de 2001. Institui o Código Municipal de Meio Ambiente e dispõe sobre a administração do uso dos recursos ambientais e ordenação do uso do solo do território do município de Arapiraca. Arapiraca, 2001.

Relatório das características ambientais do município de Arapiraca-AL. Secretaria Municipal de Desenvolvimento Urbano e Meio Ambiente. Universidade Estadual de Alagoas. Arapiraca, 2006c.

Relatório das características socioeconômicas e culturais do município de Arapiraca-AL. Secretaria Municipal de Desenvolvimento Urbano e Meio Ambiente. Universidade Estadual de Alagoas. Arapiraca, 2007. 
REZENDE, T. M.; SANTOS, D. G. Avaliação quali-quantitativa da arborização das praças do bairro Jaraguá, Uberlândia - MG. Revista da Sociedade Brasileira de Arborização Urbana, Piracicaba, v. 5 (2): 139-157, 2010.

ROMÃO, S. R. L. A cidade do futuro: agenda 21 Arapiraca. Maceió: Ideário Comunicação e Cultura, 2008.

SALDANHA, N. O jardim e a praça: o privado e o público na vida social e histórica. São Paulo: Edusp, 1993.

SILVA, R. N. Caracterização e análise da arborização em espaços públicos urbanos de Arapiraca-AL: subsídio à gestão pública. Trabalho de Conclusão de Curso (Licenciatura em Biologia). Universidade Federal de Alagoas. Arapiraca, 2011.

SILVA, R. N. Caracterização e análise quali-quantitativa da arborização em praças da área central da cidade de Arapiraca, AL. Revista da Sociedade Brasileira de Arborização Urbana, Piracicaba, v. 7 (2): 102-115, 2012.

SILVA, R. N.; GOMES, M. A. S. Parques urbanos em Alagoas: caracterização e análise no âmbito da produção do espaço. Revista Percurso, Maringá, v. 2 (1): 107-133, 2010.

ROMANI, G. N. et al. Análise quali-quantitativa da arborização na Praça XV de Novembro em Ribeirão Preto - SP, Brasil. Revista Árvore, Viçosa, v. 36 (3): 479-487, 2012.

SERPA, A. Os espaços públicos na cidade contemporânea. São Paulo: Contexto, 2007.

UGEDA JÚNIOR, J. C.; AMORIM, M. C. C. T. Avaliação dos espaços livres de construção na cidade de Jales - SP. Revista Formação Online, v. 2 (18): 99-127, 2011.

YAMAMOTO, M. A. et al. Árvores Urbanas. Piracicaba, 2004.18p. Disponível em <http://lmq.esalq.usp.br>. Acesso em: jan. 2011.

Recebido para publicação em agosto de 2012 Aprovado para publicação em setembro de 2012 
ANEXO 1 - FORMULÁRIO APLICADO NO LEVANTAMENTO DE DADOS DOS ESPAÇOS PÚBLICOS URBANOS DE ARAPIRACA-AL

Data do levantamento:

Nome do espaço público:

Endereço:

Bairro:

Perfil do imobiliário circunvizinho: （）Alto padrão （）Médio padrão （）Médio/baixo padrão （ ）Baixo padrão

Topografia do terreno: ( ) Íngreme ( ) Plana ( ) Muito íngreme

Forma geométrica: ( ) Quadrangular ( ) Circular ( ) Retangular ( ) Triangular ( ) Outra Aspecto geral do espaço público: ( ) Ótimo ( ) Bom ( ) Regular ( ) Ruim ( ) Péssimo

\begin{tabular}{|c|c|c|}
\hline Equipamentos existentes & Sim & Não \\
\hline \multicolumn{3}{|l|}{ Iluminação } \\
\hline \multicolumn{3}{|l|}{ Bancos } \\
\hline \multicolumn{3}{|l|}{ Playgrounds } \\
\hline \multicolumn{3}{|l|}{ Calçadas/caminhos } \\
\hline \multicolumn{3}{|l|}{ Lixeiras } \\
\hline \multicolumn{3}{|l|}{ Banheiros/sanitários } \\
\hline \multicolumn{3}{|l|}{ Estruturas esportivas (barras, etc.) } \\
\hline \multicolumn{3}{|l|}{ Telefone público } \\
\hline \multicolumn{3}{|l|}{ Banca de revistas } \\
\hline \multicolumn{3}{|l|}{ Quiosque de alimentação } \\
\hline \multicolumn{3}{|l|}{ Bebedouros } \\
\hline \multicolumn{3}{|l|}{ Estruturas para deficientes } \\
\hline \multicolumn{3}{|l|}{ Ponto de táxi } \\
\hline \multicolumn{3}{|l|}{ Estacionamento } \\
\hline \multicolumn{3}{|l|}{ Segurança pública (guardas, etc.) } \\
\hline \multicolumn{3}{|l|}{ Palco/coreto } \\
\hline \multicolumn{3}{|l|}{ Estruturas para idosos (jogos, etc.) } \\
\hline \multicolumn{3}{|l|}{ Monumentos } \\
\hline \multicolumn{3}{|l|}{ Placa de identificação } \\
\hline \multicolumn{3}{|l|}{ Espelho d'água/fontes } \\
\hline \multicolumn{3}{|l|}{ Ponto de ônibus } \\
\hline \multicolumn{3}{|l|}{ Vegetação } \\
\hline \multicolumn{3}{|l|}{ Árvore de grande porte } \\
\hline \multicolumn{3}{|l|}{ Árvore de médio porte } \\
\hline \multicolumn{3}{|l|}{ Árvore de pequeno porte } \\
\hline \multicolumn{3}{|l|}{ Árvores frutíferas } \\
\hline \multicolumn{3}{|l|}{ Estratos arbustivos/flores } \\
\hline Gramado & & \\
\hline
\end{tabular}

\begin{tabular}{|c|c|c|}
\hline \multicolumn{2}{|c|}{ Aspecto paisagístico geral } & Cobertura vegetal geral \\
\hline Bom & $(\mathrm{r})$ & Satisfatória ( ) \\
\hline Regular & $(\quad)$ & Insatisfatória ( ) \\
\hline Ruim & $(\quad)$ & \\
\hline
\end{tabular}

